\title{
Which exercise prescriptions improve quality of life and physical function in patients with cancer during and following treatment? A systematic review and meta-analysis of randomised controlled trials
}

\author{
Maike G Sweegers, ${ }^{1,2}$ Teatske M Altenburg, ${ }_{1}^{3}$ Mai J Chinapaw, ${ }_{1}^{3}$ Joeri Kalter, ${ }_{1}^{1,2}$ \\ Irma M Verdonck-de Leeuw, ${ }^{2,4,5}$ Kerry S Courneya, ${ }^{6}$ Robert U Newton, ${ }^{7}$ \\ Neil K Aaronson, ${ }^{8}$ Paul B Jacobsen, ${ }^{9}$ Johannes Brug, ${ }^{1,10}$ Laurien M Buffart ${ }^{1,2,7,11}$
}

- Additional material is published online only. To view please visit the journal online (http://dx.doi.org/10.1136/ bjsports-2017-097891).

For numbered affiliations see end of article.

\section{Correspondence to} Laurien M Buffart, Department of Epidemiology and Biostatistics and Medical Oncology, VU University Medical Center, De Boelelaan 1089a 1081 HV Amsterdam, The Netherlands; l.buffart@vumc.nl

Accepted 18 July 2017 Published Online First 27 September 2017
Check for updates

To cite: Sweegers MG Altenburg TM, Chinapaw MJ et al. Br J Sports Med 2018:52:505-513.

\begin{abstract}
Objective Certain exercise prescriptions for patients with cancer may improve self-reported quality of life (QoL) and self-reported physical function (PF). We investigated the effects of exercise on QoL and PF in patients with cancer and studied differences in effects between different intervention-related and exerciserelated characteristics.
\end{abstract}

Design We searched four electronic databases to identify randomised controlled trials investigating exercise effects on QoL and PF in patients with cancer. Pooled effects (Hedges' g) were calculated using Comprehensive Meta-Analysis software. Subgroup analyses were conducted based on intervention dimensions, including timing, duration and delivery mode, and exercise dimensions, including frequency, intensity, type and time (FITT factors).

Results We included 74 exercise arms. Patients who were randomised to exercise interventions had significantly improved QoL $(g=0.15,95 \% \mathrm{Cl}(0.10$ to $0.20), n=67$ exercise arms) and PF ( $g=0.21,95 \% \mathrm{Cl}$ ( 0.15 to 0.27$), n=59$ exercise arms) compared with patients in control groups. We found a significant between-group difference for exercise delivery mode, with significant beneficial effects for supervised exercise interventions ( $\mathrm{g}=0.20,95 \% \mathrm{Cl}(0.14$ to 0.26$)$ for QoL and $g=0.27,95 \% \mathrm{Cl}(0.20$ to 0.33$)$ for PF), but not for unsupervised interventions $(\mathrm{g}=0.04,95 \% \mathrm{Cl}(-0.06$ to $0.13)$ for QoL and $g=0.09,95 \% \mathrm{Cl}(-0.01$ to 0.19$)$ for $\mathrm{PF})$. No statistically significant differences in intervention effects were found for variations in intervention timing, duration or exercise FITT factors. Unsupervised exercise with higher weekly energy expenditure was more effective than unsupervised exercise with lower energy expenditure $(z=2.34, p=0.02)$.

Conclusions Exercise interventions, especially when supervised, have statistically significant and small clinical benefit on self-reported QoL and PF in patients with cancer. Unsupervised exercise intervention effects on PF were larger when prescribed at a higher weekly energy expenditure.

\section{INTRODUCTION}

Previous randomised controlled trials (RCTs) and meta-analyses have demonstrated beneficial effects of exercise during and following cancer treatment on muscle mass and strength, fatigue, cardiorespiratory fitness, physical function $(\mathrm{PF})$ and self-reported quality of life (QoL). ${ }^{1-5}$ The effect of exercise on self-reported QoL and self-reported PF may be related to characteristics of the intervention, including the timing, duration and mode of the intervention delivery, as well as exercise characteristics, including frequency, intensity, type and time (often referred to as exercise FITT factors). ${ }^{6}$

Previous systematic reviews and meta-analyses on the effects of exercise on self-reported QoL and PF during and following cancer treatment have reported small-to-moderate effects. ${ }^{278}$ The effects of exercise may vary with the specifics of the exercise intervention. ${ }^{9}{ }^{10}$ Insight into differences in effects regarding intervention-related (ie, intervention timing, duration and delivery mode) and exercise-related characteristics (ie, FITT factors) for patients with cancer is required in order to identify which exercise prescriptions are effective to improve QoL and PF. ${ }^{11}$ Unfortunately, only limited so-called second-generation studies have directly compared different intervention-related and exercise-related characteristics. For example, an RCT comparing aerobic exercise (AE) with resistance exercise (RE) in patients with prostate cancer during androgen deprivation treatment demonstrated a larger effect of RE than AE compared with usual care on QoL, ${ }^{10}$ while intervention effects did not differ significantly by exercise type in patients with breast cancer. ${ }^{12}$ Previous RCTs have also found evidence for a dose-response relationship of exercise intensity or volume on $\mathrm{QoL}^{413}$ and $\mathrm{PF}^{9}{ }^{9}$

We recently conducted an individual patient data (IPD) meta-analysis of 34 RCTs, as part of the Predicting Optimal cAncer RehabIlitation and Supportive care (POLARIS) study ${ }^{11}$ and found that exercise significantly improved self-reported QoL and PF. ${ }^{14}$ These effects were not moderated by demographic (age, sex, marital status and education) or clinical (body mass index, cancer type and treatment and presence of metastasis) characteristics. ${ }^{14}$ However, larger effects were found for supervised than for unsupervised interventions. ${ }^{14}$

While an IPD meta-analysis has the advantage of allowing standardised analytic techniques across studies and testing of interactions of the intervention with demographic and clinical characteristics at the patient level, ${ }^{14}$ it is susceptible to retrieval bias. Because not all principal investigators of 
the eligible studies were able to share their data, only $49 \%$ of eligible RCTs were included. Because intervention-related and exercise-related characteristics are set at study level, an aggregate data meta-analysis is appropriate to investigate optimal intervention and exercise characteristics and allows for the inclusion of a larger number of studies. Therefore, we conducted an aggregate data meta-analysis on RCTs identified in the POLARIS study, supplemented by more recent RCTs to further increase statistical power. We aimed to evaluate the effects of exercise on self-reported QoL and self-reported PF and to identify which specific intervention-related and exercise-related characteristics were effective for patients with cancer.

\section{METHODS}

\section{Identification and selection of studies}

We used the original search from the POLARIS study, which was conducted in 2012, to identify eligible studies ${ }^{11}$ and updated this search in January 2017. The study protocol of the POLARIS study was registered in PROSPERO in February 2013 (CRD42013003805). Details of the search strategy can be found elsewhere. ${ }^{11}$ Briefly, electronic databases of PubMed, Embase, PsycINFO and CINAHL were searched using keywords and $\mathrm{MeSH}$ terms related to neoplasms, physical fitness, exercise therapy, quality of life, randomized controlled trial and adolescent. Other sources (systematic reviews, meta-analyses, personal communication with experts, collaborators and colleagues) were searched to identify additional studies. After removing duplicates, studies were screened by title and abstract, and full-text articles were assessed for eligibility. Studies were included if the study: (1) was an RCT; (2) included adult ( $\geq 18$ years) patients with cancer; (3) evaluated the effects of an exercise intervention compared with a wait-list, usual care or attention control group; (4) included QoL and/or PF as a primary or secondary outcome measure; and (5) was written in English, German or Dutch. Because the search update yielded only one study evaluating exercise prior to cancer treatment, we excluded this RCT from the current meta-analysis.

\section{Quality assessment}

The quality assessment was performed by two independent reviewers (MGS and LMB) using the Cochrane Collaboration's tool for assessing risk of bias. ${ }^{15}$ Each study was rated on: (1) random sequence generation; (2) allocation concealment; (3) incomplete outcome data; (4) incomplete reporting; (5) adherence; and (6) contamination as other potential sources of bias, based on published papers and documentation in trial registries. The quality for each item could be rated as 'high' $(+)$, 'low' (-) or 'unclear' (?), based on the criteria presented in the online supplementary table $1 .{ }^{15}$ Items related to blinding were not included because blinding of participants and personnel is typically not feasible for exercise interventions. The rating of blinding of outcome assessment was omitted because QoL and PF are subjective constructs, measured using self-report questionnaires. Quality assessments of both reviewers were compared, and disagreements were resolved by discussion.

\section{Data extraction}

Two independent reviewers (MGS and LMB or MGS and TMA) extracted information about the country where the RCT was conducted, the sample size, cancer type, mean age, sex, type of control group and the questionnaires used to measure QoL and $\mathrm{PF}$, as well as the timing, mode and duration of intervention delivery and exercise FITT factors.

\section{Outcome measure}

Both QoL, including general health, global and overall QoL and PF were self-reported. The general health and PF subscale from the generic Short-Form 36 (SF-36) ${ }^{16}$ were used as measures of self-reported QoL and self-reported PF, respectively. The total score from the Quality of Life Index ${ }^{17}$ and the Spitzer QoL uniscale $^{18}$ were used as measures for QoL. The global QoL and $\mathrm{PF}$ scales from the disease-specific European Organisation for Research and Treatment of Cancer QLQ-C30 questionnaire ${ }^{19}$ and Cancer Rehabilitation Evaluation System short form ${ }^{20}$ were used as measures of self-reported QoL and self-reported PF. The total score from the Functional Assessment of Cancer Therapy-General (FACT-G) ${ }^{21}$ was used as a measure for self-reported QoL, and the physical well-being scale was used as a measure of self-reported PF. These questionnaires are reliable and valid measures of QoL and PF. ${ }^{16-21}$ If both a generic and a disease-specific questionnaire were used to measure QoL and $\mathrm{PF}$, we included results from the disease-specific questionnaire in the analyses. In cases where the total QoL score from the FACT-G questionnaire was not presented separately from the results of the tumour-specific modules (eg, total FACT-Breast or FACT-Prostate score), we used the latter score as a measure of QoL. In cases where the PF subscale of the SF-36 was not reported, the physical component summary score was used in the pooled analyses on PF. ${ }^{16}$

\section{Statistical analysis}

We calculated effect sizes for all individual studies by subtracting the average postintervention score of the control group from the average postintervention score of the intervention group and dividing the result by the pooled SD of the intervention and control group. ${ }^{22}$ All effect sizes were pooled using Hedges' g, thereby adjusting for studies with a small sample size. ${ }^{23}$ Using Cohen's convention, we interpreted an effect size of 0.2 as small, 0.5 as moderate and 0.8 as large. ${ }^{24} 25$ When average scores or SD were not reported, we investigated whether other statistics could be used to calculate effect sizes (ie, average scores and 95\% CI, between-group differences and $\mathrm{p}$ values). When results on self-reported QoL or PF were reported incompletely, the principal investigator of the study was contacted. Because the samples and interventions were expected to be heterogeneous, effect sizes were pooled with a random effects model, taking any systematic difference in the effects between the studies into consideration. The $\mathrm{I}^{2}$ statistic was reported as an indicator of heterogeneity, with an $\mathrm{I}^{2}$ of $25 \%$ representing low, $50 \%$ representing moderate and $75 \%$ representing high heterogeneity. ${ }^{26}$ Studies were considered outliers if the $95 \% \mathrm{CI}$ of the effect did not overlap with the $95 \%$ CI of the pooled effect and were excluded from further analyses. All analyses were conducted using Comprehensive Meta-Analysis software (V.2.2.064).

We studied differences in effects between subgroups based on intervention timing (categorised into during, following and combined during and following cancer treatment according to the physical activity and cancer control framework developed by Courneya and Friedenreich ${ }^{27}$ ), duration (categorised into $\leq 12$, $>12-24$ and $>24$ weeks), delivery mode (ie, supervised when multiple face-to-face supervised exercise sessions over time were included vs unsupervised when there was no instructor or exercise specialist present during exercise) and exercise FITT factors. Exercise frequency of supervised exercise sessions was dichotomised into $<3$ and $\geq 3$ times/week and unsupervised interventions into $<5$ and $\geq 5$ times/week. Exercise intensity was categorised into low and low-moderate versus moderate versus 
moderate-high and high intensity using the American College of Sports Medicine guidelines (online supplementary table 2), ${ }^{28}$ exercise type was categorised into $\mathrm{AE}, \mathrm{RE}, \mathrm{AE}+\mathrm{RE}$ and $\mathrm{RE}+\mathrm{im}-$ pact loading exercises (ie, two-footed jumps with weighted vests) and exercise time (ie, session duration) into $\leq 30,30-60$ and $>60 \mathrm{~min}$. In case a statistically significant difference in effects was found between subgroups, we reported the effects stratified per subgroup. Meta-regression analyses were used to study whether the effect was influenced by the weekly exercise volume (ie, frequency $\times$ time) and weekly energy expenditure (ie, frequency $\times$ intensity $\times$ time). To estimate intensity, we used metabolic equivalents (METs) in which a value of 1.5 METs was used to indicate low intensity, 3 METs to indicate low-to-moderate intensity, 4.5 METs for moderate intensity, 6 METs for moderate-to-high intensity and 7.5 METs for high intensity exercise. ${ }^{29}$ We reported $z$-values, which express the statistically significance of the slope of the relationship between the variable (ie, exercise volume or exercise intensity) and the effect size. As there is some evidence that the effects of exercise on QoL and PF vary with cancer type, ${ }^{81012}$ we checked whether there were differences in effects between exercise intervention characteristics across cancer types and performed a sensitivity analysis in studies that only included patients with breast cancer as the majority of included RCTs (44\%) focused on this type of cancer.

We investigated publication bias by inspecting the funnel plot and calculated the effect size with a correction for possible publication bias using Duval and Tweedie's procedure. ${ }^{30}$ This procedure trims (removes) studies in case of asymmetry in the funnel plot, estimates the true 'centre' of the funnel and replaces (fills) the omitted studies around the centre. A statistically significant dispersion between the true effect size and the calculated effect size after correcting for possible missing studies or an asymmetry in the funnel plot, calculated using Egger's test, could suggest publication bias. An alpha level of $\mathrm{p} \leq 0.05$ was applied as the criterion for statistical significance.

\section{RESULTS}

\section{Description of study inclusion (figure 1)}

The original search from the POLARIS study resulted in 69 RCTs investigating the effect of exercise compared with a control group, all of which were included in the current meta-analysis. The search update identified 389 additional studies of which 33 were eligible. We also included two additional studies via personal communication. After removing duplicates $(n=18)$ and unpublished RCTs $(n=2), 84$ studies were retrieved of which $9^{101231-37}$ studies investigated 2 exercise arms, leading to a total of 93 exercise arms that were compared with a usual care, waitlist or attention control group.

The principal investigators of 26 studies were contacted because of incomplete reporting of both $\mathrm{QoL}$ and PF data, and 21 principal investigators were contacted because only self-reported QoL or PF was reported. After personal communication, we obtained additional information for $17^{123132353638-49}$ studies, leading to an exclusion of $18^{3450-65}$ exercise arms. Finally, this meta-analysis included 66 RCTs, investigating 74 exercise arms ( $n=6509$ patients), of which 71 exercise arms examined QoL and 64 exercise arms examined PF.

\section{Quality assessment of studies included in the meta-analysis}

A random sequence generator was used in 54 studies (82\%) and allocation of randomisation was concealed in 45 studies (68\%) (online supplementary table 3 ). In 49 studies (74\%), missing data were limited $(<10 \%)$ or an appropriate imputation method was used. Eight studies (12\%) incompletely reported QoL and $\mathrm{PF}$, and an additional 21 studies (32\%) only reported QoL or PF. Twenty-four studies (36\%) had high adherence, and 13 studies (20\%) had low contamination. Study characteristics and quality assessment of 19 $9^{345-66}$ exercise arms not included in the meta-analyses are presented in the online supplementary table 4 .

\section{Characteristics of exercise arms included in the meta-analysis}

As exercise arms are used as separate entities in the current meta-analysis, this paragraph will describe intervention characteristics for each study arm. Characteristics of the exercise arms included in the meta-analysis are presented in online supplementary table 3. Sample size ranged from 14 to 295 . Patients were, on average, 55 years old and $68 \%$ was female. On average, recruitment rate and dropout rate were $52 \%$ and $13 \%$, respectively, and did not differ significantly between studies investigating patients with different types of cancer. Twenty-nine 3123132363741434648 ${ }^{67-80}$ exercise arms evaluated the effects of exercise interventions in patients with breast cancer, $10^{1081-88}$ in patients with prostate cancer, $5^{4789-92}$ in patients with lung cancer, $15^{38} 454993-100$ in patients with other types of cancer (bladder $(n=1)$, colorectal $(\mathrm{n}=3)$, haematological $(\mathrm{n}=7)$, head and neck $(\mathrm{n}=1)$ and gynaecological $(\mathrm{n}=1)$ ) and $15^{435} 394042101-108$ in patients with various types of cancers. Thirty-three ${ }^{10} 123537394044486772747578-83$ 85-88 919596101102107109 exercise arms investigated the effects of an exercise intervention during cancer treatment, $32^{3431363841-43}$ 45-47 68-71 73 767784899294100103-106110111 following treatment and $9^{32} 49909397-99108$ during and following cancer treatment. Intervention duration was $\leq 12$ weeks in 42, 431373841444547686971 $727477-81838586899192949698-102104-110>12-24$ weeks in $24^{3} 10$ 1235363940424967707582848890939597103 and $>24$ weeks in $8^{32} 43$ 4648737687

investigated in $52^{3} 410123135374143-464968$ 70-75 77-88 90-92 95-97 99 100102 104-106 109-111

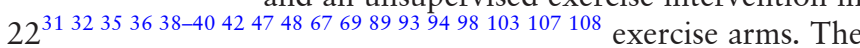
frequency of supervised exercise sessions was $<3$ times per week in $29^{435} 374143454672-7678-848795100102104106109110$ and $\geq 3$ times per week in $23^{3} 10123144496870717785868890-929699101105111$ exercise arms. The frequency of unsupervised exercise sessions was $<5$ times per week in $9^{31323842489394108}$ and $\geq 5$ times per week in $11^{353639406789} 9798103107$ exercise arms. Two 4769 studies investigating an unsupervised exercise intervention did not describe the frequency of exercise prescription. Prescribed exercise intensity was low in $1^{72}$ study arm, low-to-moderate in 9, 4044829699100104105111 moderate in 34, $10313235-384347486770$ 7783 86-88 91-9398102103108109 moderate-to-high in $16^{3} 12424968$ 74-7678 808184899597 and high in $8^{4103537697990101}$ exercise arms. Five 3945467173 exercise arms did not report any information on exercise intensity. Twenty-six 31012313537 39-41 49 67-70 77-7985 8993 94 102-105 108 exercise arms investigated the effect of AE, $12^{101237}$ 46737480868899100109 investigated RE, $33^{43132363842444547487172}$ 75 81-84 90-92 95-98 101106107110111 investigated a combined AE and RE programme and $3^{437687}$ investigated RE+impact exercises. Session duration was reported as $\leq 30 \mathrm{~min}$ in 29,3101231353638 $404249677077-798993949798103-10510811011130-60 \mathrm{~min}$ in $31^{43132}$ $35373943-4548687274-7680-858790959699101102$ and >60 min in $3^{41}$ 46106 exercise arms. Eleven 4769717386889192100107109 studies did not report information on session duration. The mean volume of exercise per week was $121 \mathrm{~min}(\mathrm{SD}=48)$ for supervised exercise and $132 \mathrm{~min}(\mathrm{SD}=37)$ for unsupervised exercise, and the mean weekly energy expenditure was 637 MET-minutes/week $(\mathrm{SD}=313)$ for supervised exercise and $615 \mathrm{MET}$-minutes/week $(\mathrm{SD}=248)$ for unsupervised exercise. 


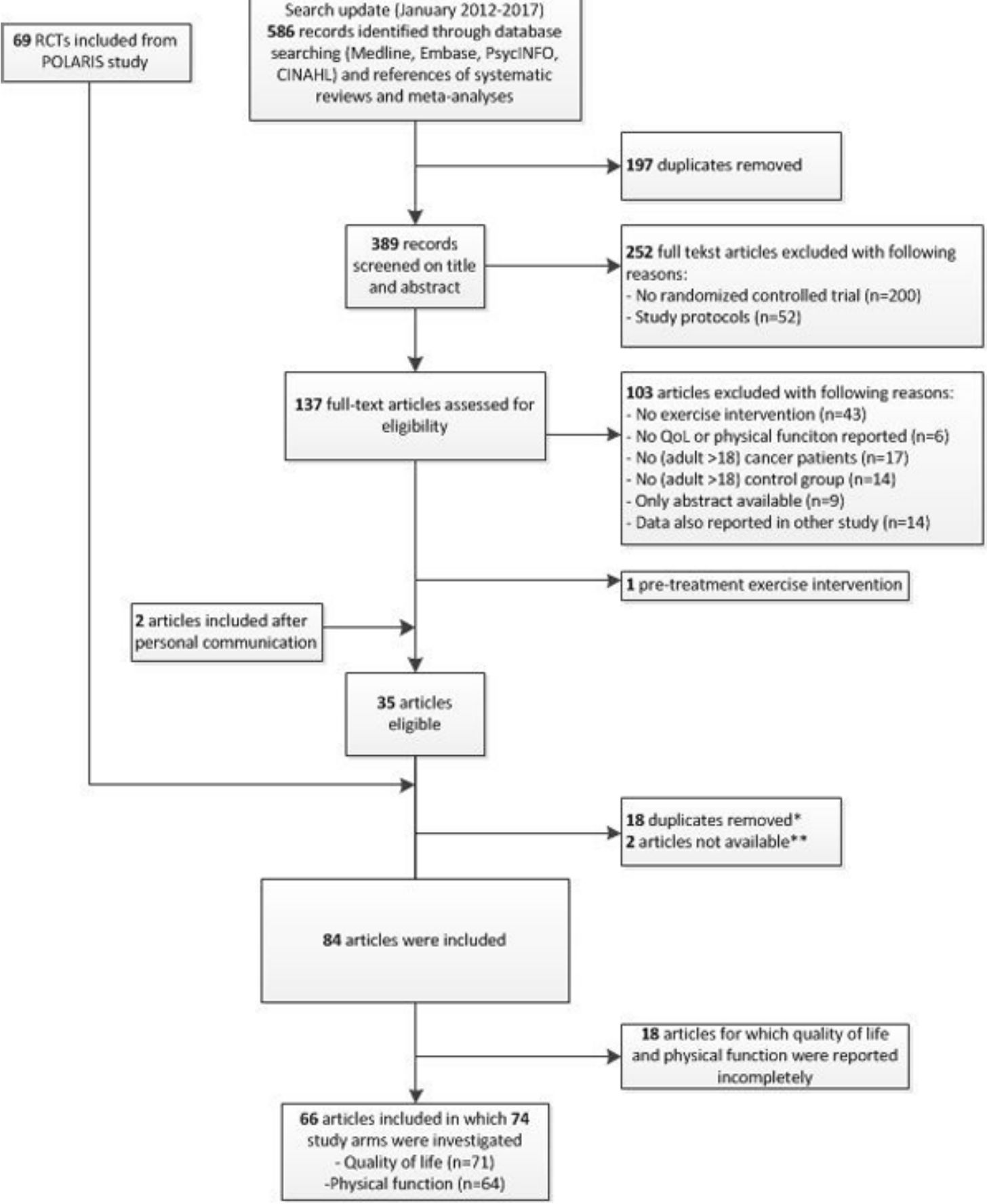

Figure 1 Flow chart of study inclusion. *Studies were not yet published in 2012; however, within POLARIS, we maintained contact about the study completion date, and these studies were included at a later stage. ** Data from two studies were included in POLARIS but full text is not yet available. POLARIS, Predicting Optimal Cancer Rehabllitation and Supportive care; QoL, quality of life; RCTs, randomised controlled trials.

\section{Publication bias}

Data on QoL were available for 67 exercise arms after excluding four $^{717778} 105$ outliers of which the CI did not overlap with the pooled effect, and data on PF were available for 59 exercise arms after excluding five 35497190108 outliers. We found small, statistically significant beneficial effects on QoL ( $g=0.15,95 \%$ CI $(0.10$ to 0.20$)$, figure $2 \mathrm{~A})$ and $\mathrm{PF}(\mathrm{g}=0.21,95 \% \mathrm{CI}(0.15$ to 0.27 ), figure $2 \mathrm{~B}$ ).

For exercise arms evaluating QoL, the Duvall and Tweedie's trim and fill procedure suggested six trials were missing, resulting in an effect size of $\mathrm{g}=0.13(95 \% \mathrm{CI}(0.08$ to 0.18$)$ ) after adjusting for possible publication bias. Egger's test was not statistically significant $(p=0.22)$, suggesting no evidence of publication bias. Regarding PF, the Duvall and Tweedie's trim and fill procedure suggested two trials were missing, resulting in an effect size of $\mathrm{g}=0.21$ (95\% CI (0.14 to 0.27)) after adjusting for possible publication bias. Egger's test was not statistically significant $(p=0.26)$, again suggesting no evidence of publication bias.

\section{Effect of exercise on self-reported QoL and PF}

Intervention effects on self-reported QoL and PF did not differ significantly between types of cancer, the timing of intervention 
A

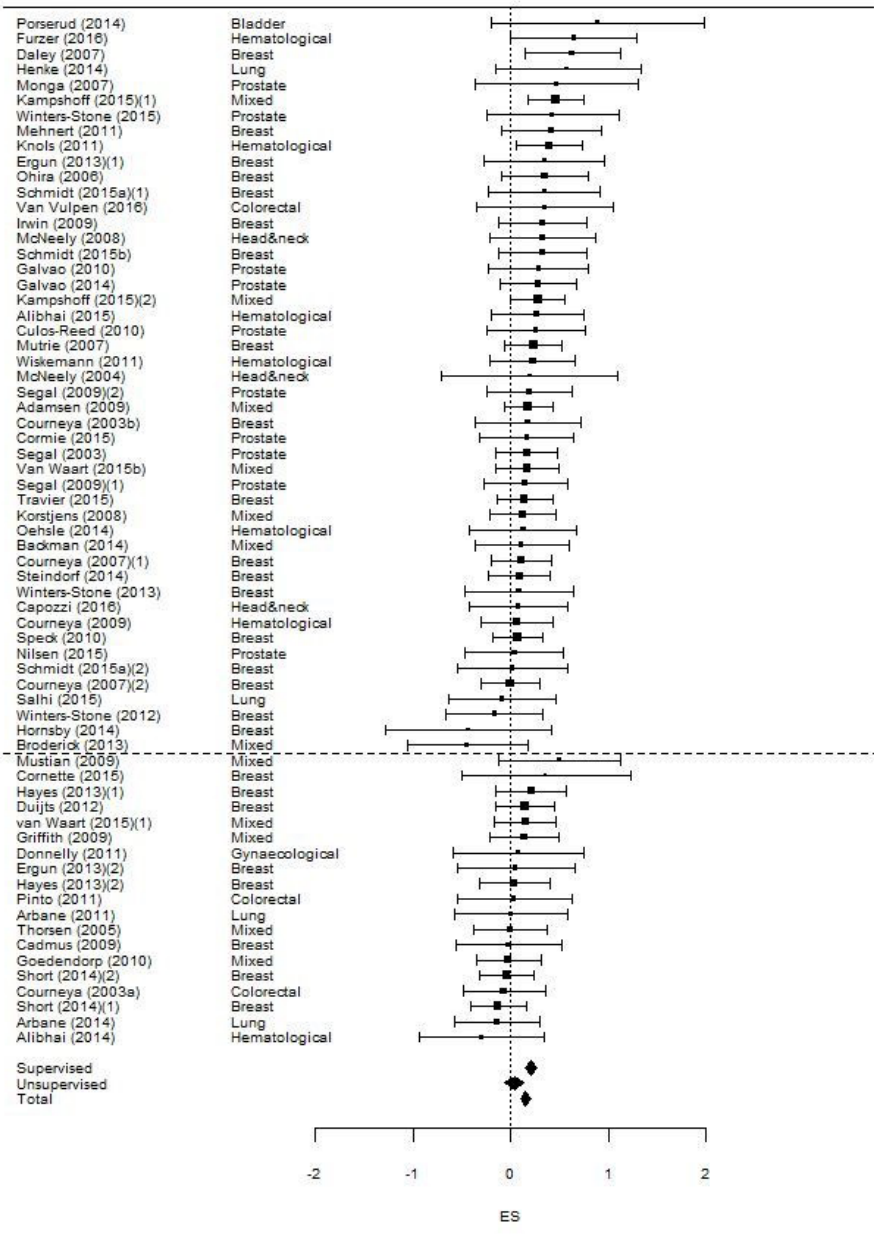

B

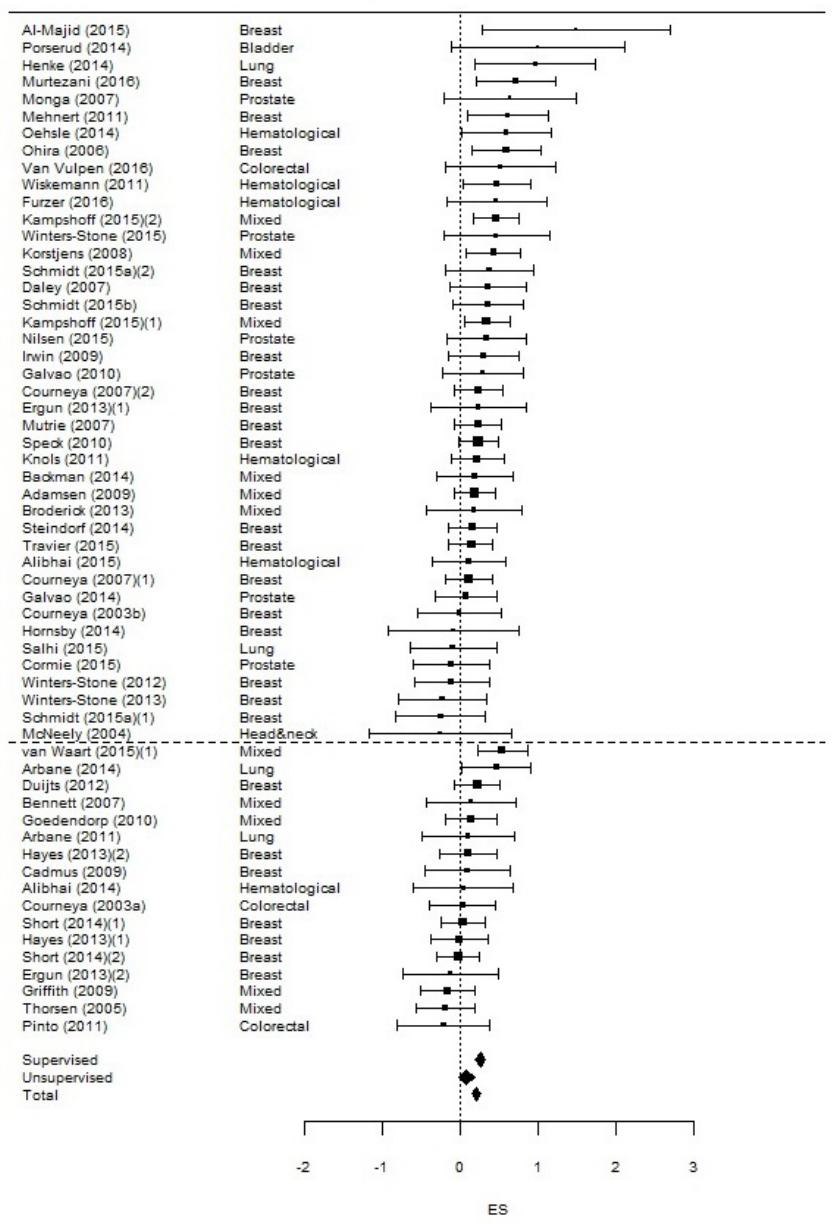

Figure 2 Comparison of effect sizes on quality of life (A) and physical function (B) for studies investigating supervised (above dashed line) versus unsupervised (below dashed line) exercise: Hedges' $\mathrm{g}$ and $95 \% \mathrm{Cl}$.

delivery or intervention duration (table 1 ). The effects of supervised exercise on self-reported QoL $(\mathrm{p}<0.01)$ and $\mathrm{PF}(\mathrm{p}=0.01)$ were significantly larger than the effects of unsupervised exercise. Supervised exercise significantly improved QoL $(\mathrm{g}=0.20$, $95 \% \mathrm{CI}(0.14$ to 0.26$)$ ) and PF ( $\mathrm{g}=0.27,95 \% \mathrm{CI}(0.20$ to 0.33$)$ ), while the effect of unsupervised exercise was not statistically significant for self-reported QoL $(\mathrm{g}=0.04,95 \%$ CI $(-0.06$ to $0.13)$ ) nor $\mathrm{PF}$ ( $\mathrm{g}=0.09,95 \% \mathrm{CI}(-0.01$ to 0.19$)$ ).

Stratified analyses showed no statistically significant differences in effects on self-reported QoL and PF between interventions with various exercise FITT factors for both supervised and unsupervised exercise interventions. The effects on PF were larger for exercise interventions with a duration of $\leq 12$ weeks than exercise interventions with a longer duration $(p=0.08)$. However, no statistically significant between group difference for intervention duration was found when it was studied separately for supervised $(\mathrm{p}=0.49)$ and unsupervised exercise $(\mathrm{p}=0.71)$.

Meta-regression analysis showed that the effects of unsupervised exercise on PF was significantly larger for exercise interventions with a higher weekly energy expenditure $(Z=2.34$, $\mathrm{p}=0.02$ ) (figure 3 ) but not weekly exercise volume. The effect of exercise on self-reported QoL did not differ by weekly exercise volume or energy expenditure.
Sensitivity analyses in a subgroup of studies that included patients with breast cancer only showed comparable effect sizes. However, the difference in effect on self-reported QoL between supervised and unsupervised exercise $(p=0.13)$ as well as the association between weekly energy expenditure and the effects of unsupervised exercise on PF $(\mathrm{Z}=1.08, \mathrm{p}=0.28)$ were not statistically significant.

\section{DISCUSSION}

The current meta-analysis synthesised the data from 66 RCTs, including 74 exercise arms that evaluated the effects of exercise interventions during and following cancer treatment on self-reported QoL and PF. The large number of studies allowed us to study differences in effects across the timing, duration and mode of intervention delivery and exercise FITT factors.

\section{Main finding}

We found statistically significant and small clinical benefits of exercise interventions on self-reported QoL and PF. Supervised exercise interventions had statistically significant beneficial effects on QoL and PF, while unsupervised exercise interventions had no statistically significant beneficial effects on QoL and PF. We found no evidence for differences in effects between 
Table 1 Pooled effects of exercise on quality of life and physical function in patients with cancer during and post-treatment

\begin{tabular}{|c|c|c|c|c|c|c|c|c|}
\hline \multirow[b]{2}{*}{ Comparison } & \multicolumn{4}{|c|}{ Quality of life } & \multicolumn{4}{|c|}{ Physical function } \\
\hline & $N$ & $\mathrm{~g}(95 \% \mathrm{Cl})$ & $I^{2}$ & $\begin{array}{l}\text { Between-group } \\
\text { difference }(p)\end{array}$ & $\mathrm{N}$ & $\mathrm{g}(95 \% \mathrm{Cl})$ & $I^{2}$ & $\begin{array}{l}\text { Between-group } \\
\text { difference }(p)\end{array}$ \\
\hline Overall & 71 & $0.19(0.13 \text { to } 0.26)^{*}$ & $37.93^{*}$ & & 64 & $0.26(0.18 \text { to } 0.35)^{*}$ & $58.75^{*}$ & \\
\hline Overall without outliers & $67^{71} 7778105$ & $0.15(0.10 \text { to } 0.20)^{*}$ & 0.00 & & $59^{3549} 7190108$ & $0.21(0.15 \text { to } 0.27)^{*}$ & 15.87 & \\
\hline Diagnosis & & & & 0.70 & & & & 0.60 \\
\hline Timing & & & & 0.81 & & & & 0.61 \\
\hline During & 32 & $0.16(0.08 \text { to } 0.23)^{*}$ & 0.00 & & 25 & $0.22(0.13 \text { to } 0.32)^{*}$ & 12.76 & \\
\hline During-post & 7 & $0.10(-0.07$ to 0.26$)$ & 0.00 & & 5 & $0.12(-0.08$ to 0.31$)$ & 0.00 & \\
\hline Post & 28 & $0.16(0.06 \text { to } 0.25)^{*}$ & 21.43 & & 29 & $0.21(0.12 \text { to } 0.31)^{*}$ & 23.64 & \\
\hline Intervention duration (week) & & & & 0.10 & & & & 0.08 \\
\hline$\leq 12$ & 38 & $0.21(0.13 \text { to } 0.28)^{*}$ & 0.00 & & 34 & $0.28(0.20 \text { to } 0.36)^{*}$ & 6.09 & \\
\hline $13-\leq 24$ & 21 & $0.09(0.01 \text { to } 0.17)^{*}$ & 0.00 & & 18 & $0.14(0.05 \text { to } 0.23)^{*}$ & 11.61 & \\
\hline$>24$ & 8 & $0.12(-0.02$ to 0.27$)$ & 0.00 & & 7 & $0.16(-0.03$ to 0.34$)$ & 30.67 & \\
\hline Delivery mode & & & & $<0.01$ & & & & 0.01 \\
\hline Supervised & 48 & $0.20(0.14 \text { to } 0.26)^{*}$ & 0.00 & & 42 & $0.27(0.20 \text { to } 0.33)^{*}$ & 3.20 & \\
\hline Unsupervised & 19 & $0.04(-0.06$ to 0.13$)$ & 0.00 & & 17 & $0.09(-0.01$ to 0.19$)$ & 11.29 & \\
\hline \multicolumn{9}{|l|}{ Supervised } \\
\hline Frequency (times/week) & & & & 0.76 & & & & 0.59 \\
\hline$<3$ & 28 & $0.21(0.13 \text { to } 0.28)^{*}$ & 0.00 & & 24 & $0.26(0.17 \text { to } 0.34)^{*}$ & 0.00 & \\
\hline$\geq 3$ & 20 & $0.19(0.09 \text { to } 0.28)^{*}$ & 0.00 & & 18 & $0.30(0.18 \text { to } 0.42)^{*}$ & 11.43 & \\
\hline Intensity & & & & 0.85 & & & & 0.38 \\
\hline Low-moderate & 8 & $0.22(0.04 \text { to } 0.39)^{*}$ & 31.70 & & 6 & $0.26(0.06 \text { to } 0.46)^{*}$ & 0.00 & \\
\hline Moderate & 18 & $0.23(0.13 \text { to } 0.34)^{*}$ & 0.00 & & 16 & $0.33(0.19 \text { to } 0.47)^{*}$ & 18.04 & \\
\hline Moderate-high & 19 & $0.17(0.09 \text { to } 0.26)^{*}$ & 0.00 & & 17 & $0.21(0.11 \text { to } 0.30)^{*}$ & 0.00 & \\
\hline Type & & & & 0.27 & & & & 0.53 \\
\hline $\mathrm{AE}$ & 12 & 0.18 (0.03 to 0.32$)^{*}$ & 7.14 & & 12 & $0.28(0.10 \text { to } 0.47)^{*}$ & 28.87 & \\
\hline RE & 12 & $0.13(0.02 \text { to } 0.24)^{*}$ & 0.00 & & 8 & $0.27(0.14 \text { to } 0.41)^{*}$ & 0.00 & \\
\hline$A E+R E$ & 21 & $0.26(0.17 \text { to } 0.34)^{*}$ & 0.00 & & 19 & $0.28(0.19 \text { to } 0.38)^{*}$ & 0.00 & \\
\hline $\mathrm{RE}+$ impact & 3 & $0.06(-0.27$ to 0.38$)$ & 0.00 & & 3 & $0.00(-0.37$ to 0.37$)$ & 21.79 & \\
\hline Time (min/session) & & & & 0.58 & & & & 0.54 \\
\hline$\leq 30$ & 12 & $0.15(0.02 \text { to } 0.27)^{*}$ & 4.43 & & 11 & $0.29(0.14 \text { to } 0.43)^{*}$ & 9.26 & \\
\hline $30-\leq 60$ & 26 & $0.24(0.15 \text { to } 0.32)^{*}$ & 0.00 & & 24 & $0.23(0.14 \text { to } 0.31)^{*}$ & 0.00 & \\
\hline \multirow[t]{2}{*}{$>60$} & 3 & $0.13(-0.05$ to 0.32$)$ & 0.00 & & 3 & $0.35(0.16 \text { to } 0.54)^{*}$ & 1.95 & \\
\hline & & Z-value & & & & Z-value & & \\
\hline $\begin{array}{l}\text { Weekly exercise volume (regression) } \\
\text { minutes/week }\end{array}$ & 40 & 0.43 & & & 37 & 0.69 & & \\
\hline $\begin{array}{l}\text { Weekly energy expenditure (regression) } \\
\text { MET-minutes/week }\end{array}$ & 38 & 0.45 & & & 35 & 0.10 & & \\
\hline \multicolumn{9}{|l|}{ Unsupervised } \\
\hline Frequency (times/week) & & & & 0.77 & & & & 0.23 \\
\hline$<5$ & 8 & $0.04(-0.12$ to 0.21$)$ & 0.00 & & 7 & $-0.03(-0.20$ to 0.14$)$ & 0.00 & \\
\hline$\geq 5$ & 9 & $0.02(-0.11$ to 0.14$)$ & 0.00 & & 7 & $0.15(-0.04$ to 0.35$)$ & $54.02^{*}$ & \\
\hline Intensity & & & & 0.93 & & & & 0.55 \\
\hline Low-moderate & 1 & $0.14(-0.21$ to 0.49$)$ & & & 1 & $-0.15(-0.50$ to 0.20$)$ & 0.00 & \\
\hline Moderate & 14 & $0.03(-0.08$ to 0.15$)$ & 0.00 & & 12 & $0.10(-0.02$ to 0.21$)$ & 0.00 & \\
\hline Moderate-high & 3 & $0.04(-0.16$ to 0.25$)$ & 0.00 & & 3 & $0.17(-0.18$ to 0.51$)$ & 61.01 & \\
\hline Type & & & & 0.70 & & & & 0.16 \\
\hline $\mathrm{AE}$ & 9 & $0.06(-0.08$ to 0.19$)$ & 0.00 & & 10 & $0.16(-0.01$ to 0.32$)$ & 33.83 & \\
\hline $\mathrm{RE}$ & 0 & & & & 0 & & & \\
\hline$A E+R E$ & 10 & $0.02(-0.11$ to 0.15$)$ & 0.00 & & 7 & $0.01(-0.13$ to 0.14$)$ & 0.00 & \\
\hline Time (min/session) & & & & 0.34 & & & & \\
\hline$\leq 30$ & 12 & $-0.01(-0.10$ to 0.13$)$ & 0.00 & & 11 & $0.07(-0.09$ to 0.23$)$ & 40.39 & \\
\hline \multirow[t]{2}{*}{$30-\leq 60$} & 4 & $0.08(-0.11$ to 0.28$)$ & 0.00 & & 3 & $0.09(-0.12$ to 0.29$)$ & 0.00 & 0.69 \\
\hline & & Z-value & & & & Z-value & & \\
\hline $\begin{array}{l}\text { Weekly exercise volume (regression) } \\
\text { minutes/week }\end{array}$ & 16 & -0.66 & & & 15 & 1.87 & & \\
\hline $\begin{array}{l}\text { Weekly energy expenditure (regression) } \\
\text { MET-minutes/week }\end{array}$ & 16 & -0.27 & & & 15 & $2.34^{*}$ & & \\
\hline
\end{tabular}

\section{${ }^{*} \mathrm{p} \leq 0.05$.}

$A E$, aerobic exercise; $g$, Hedges' $g$; $l^{2}$, indicator of heterogeneity; MET, metabolic equivalent; $n$, number of studies included; RE, resistance exercise. 
A

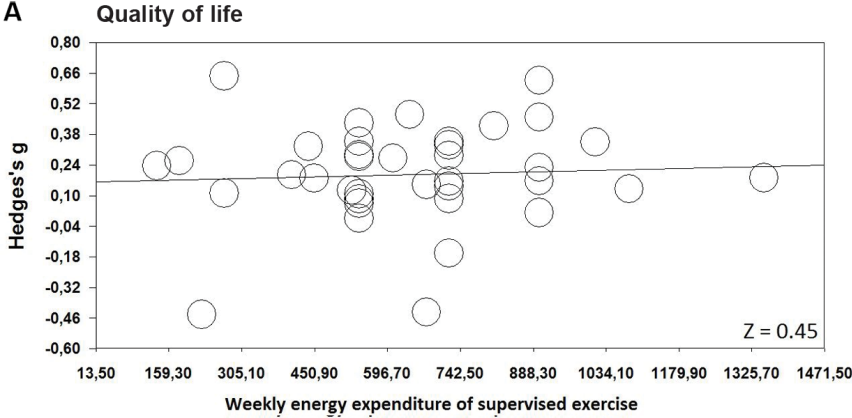

B Weekly energy expenditure of supervised exercise
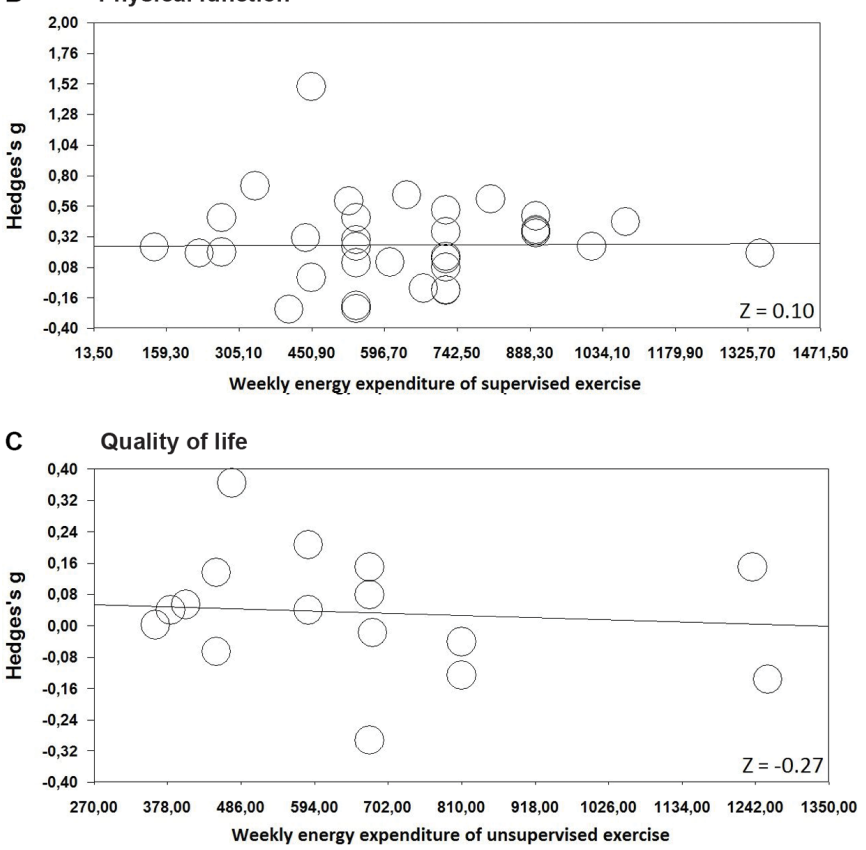

D

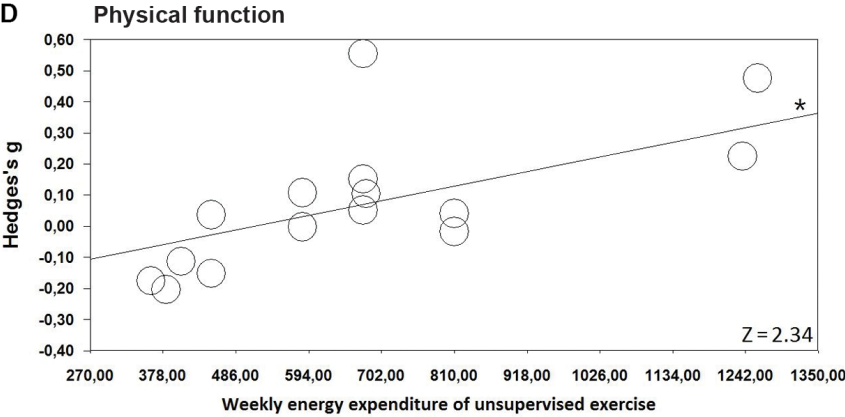

Figure 3 The association between weekly energy expenditure and the effect of exercise on self-reported quality of life and physical function. (A) Weekly energy expenditure and the effect of supervised exercise on quality of life. (B) Weekly energy expenditure and the effect of supervised exercise on physical function. (C) Weekly energy expenditure and the effect of unsupervised exercise on quality of life. (D) Weekly energy expenditure and the effect of unsupervised exercise on physical function. * statistical significant association between weekly energy expenditure and the effect of exercise.

subgroups formed on the basis of intervention timing, duration or exercise FITT factors. However, within the category of unsupervised exercise interventions, there were larger effects on PF for interventions with a higher prescribed weekly energy expenditure.

The results from the current meta-analysis strengthen the findings from our previous IPD meta-analysis by including 32 additional RCTs, thereby increasing power to identify optimal intervention-related and exercise-related characteristics. ${ }^{14}$ The small effect sizes (QoL: 0.15, PF: 0.21) found in our meta-analysis are in line with those reported in our previous IPD meta-analysis and in a previous meta-analysis by Speck et al. ${ }^{2}$ However, Mishra et al reported moderate effect sizes in the meta-analyses of the effects of exercise during ${ }^{8}$ and following ${ }^{7}$ cancer treatment, which may be caused by our decision to exclude the outliers and the use of Hedges' $g$ to adjust for studies with small sample sizes. In addition, RCTs using objective measurement of PF such as gait speed, stair climb or chair-rise tests found larger effect sizes. ${ }^{53818384}$ Possibly, patients may not perceive large improvements in PF over time or self-reported PF may be susceptible to a response shift. ${ }^{112}$

\section{No differences in effect of timing, duration or delivery mode of treatment}

In line with a previous RCT $^{49}$ and other (IPD) meta-analyses, ${ }^{27814}$ we found no evidence for differences in effects on QoL or PF between studies that investigated exercise interventions during, following or both during and following cancer treatment. This finding suggests that exercise may contribute to preventing a decrease in self-reported QoL and PF during treatment as well as to improving QoL and PF following cancer treatment. ${ }^{113}$ Additionally, it was not possible to distinguish between the different types of treatment (eg, chemotherapy, radiation therapy, immune or hormone therapy) that may have influenced our results.

\section{Mechanisms that underpin our main finding}

Larger effects of supervised compared with unsupervised exercise interventions were also reported in our previous IPD meta-analysis ${ }^{14}$ and may be explained by a more demanding exercise prescription, a higher compliance to the prescribed exercise intervention, access to better equipment with more adjustment and performance feedback, the attention and support of the exercise physiologist delivering the intervention and possibly social interaction with other participants. ${ }^{114}$ One of the included RCTs found no statistically significant difference on QoL between an exercise placebo (including body conditioning/ stretching exercises) and a usual care control group, ${ }^{68}$ indicating that attention was probably not, in itself, responsible for the beneficial effects of exercise on QoL. Previous RCTs comparing a supervised $\mathrm{AE}$ and $\mathrm{RE}$ programme with an unsupervised $\mathrm{AE}$ programme reported larger effects of supervised compared with unsupervised exercise on QoL following treatment ${ }^{31}$ and PF during treatment. ${ }^{35}$ However, this difference could also be due to differences in exercise types. To identify the effects of the supervision, we recommend a head-to-head comparison of supervised and unsupervised exercise with identical exercise-related characteristics in patients with cancer. In addition, objective methods for assessing exercise intensity and duration (eg, accelerometry and heart rate monitoring) could assess the compliance to the prescribed exercise intervention. This could help to compare the exercise undertaken by patients when following a supervised or unsupervised exercise programme and to investigate the effects of the supervision.

\section{Differences in effects of exercise characteristics}

We found no evidence for a difference in effect between different exercise types, and both supervised $\mathrm{AE}$ and $\mathrm{RE}$ resulted in a statistically significant increase in self-reported QoL and PF. 
This finding is in contrast to the findings of a previous RCT, reporting larger effects of RE compared with usual care than $\mathrm{AE}$ on $\mathrm{QoL}$ in patients with prostate cancer receiving radiation therapy, ${ }^{10}$ but in line with results from previous studies comparing $A E$ with $\mathrm{RE}^{12}$ and $\mathrm{AE}$ with $\mathrm{AE}+\mathrm{RE}^{9}$ in patients with breast cancer receiving chemotherapy. However, the effects of different exercise types on other outcomes such as aerobic fitness, percentage body fat, muscle strength and lean body mass may differ, as has been reported by Courneya $e t$ al in patients with breast cancer. ${ }^{12}$

For unsupervised exercise interventions, we found evidence for larger intervention effects on PF when weekly energy expenditure prescriptions were higher, while there was no evidence for an effect of high-intensity exercise or a high weekly exercise volume alone. This finding suggests that, in the case of unsupervised exercise, patients should be encouraged to increase their weekly energy expenditure when aiming to improve PF. However, the optimal combination of weekly exercise volume and exercise intensity for unsupervised interventions is still unclear. For supervised exercise, no dose-response relationship was found between weekly energy expenditure and the effect on self-reported QoL or PF. A previous RCT reported a higher dose of supervised $\mathrm{AE}$ to be related to larger effects on $\mathrm{PF},{ }^{9}$ while a higher frequency (3 vs 2 days/week) of RE was related to higher effects on the physical component summary (including PF). ${ }^{115}$ In the current meta-analysis, the dose-response relationship between weekly energy expenditure and the effect of exercise on self-reported QoL and PF was investigated for $\mathrm{AE}$ and RE combined. Future research should clarify whether this relationship differs by exercise type.

Exercise seems equally effective in improving self-reported QoL and PF across patients with different cancer types, which extends the conclusion of our previous IPD meta-analysis. ${ }^{14}$ Sensitivity analyses in patients with breast cancer showed comparable effect sizes. However, most likely due to larger confidence levels, the difference in effect between supervised and unsupervised exercise interventions on QoL, was not statistically significant. Comparably, the dose-response relationship of weekly energy expenditure and the effect on PF were not statistically significant in patients with breast cancer.

It is important to note that some RCTs reported low recruitment rates without describing demographic or clinical differences between participants and non-participants to inform generalisability of the results. Previous RCTs investigating the effects of an exercise intervention during or following cancer treatment in patients with cancer on physical fitness, fatigue and QoL reported that non-participants are more likely to have a low educational level, are less likely to be working, have longer travel time, live alone, have more comorbidities than participants and are often aged $\geq 70$ years. ${ }^{35}{ }^{116}$ Additionally, sex and diagnosis did not differ between participants and non-participants in patients with different diagnosis. ${ }^{4}$ As most previous studies did not report the reasons for dropout, we were unable to provide information on the characteristics of participants who dropped out of the exercise trials. From a previous systematic review investigating the determinants of exercise adherence, it is known that exercise history is a main determinant of adherence, but the results for baseline cardiorespiratory fitness and physical activity were unclear. ${ }^{117}$ Studies investigating exercise interventions in patients with a poor prognosis (such as pancreatic or lung cancer) are scarce, and some caution is warranted with generalising the results to all cancer populations. Future research should focus on the effects of exercise in patients with understudied cancer types.
The lack of statistically significant differences in exercise intervention effects as a function of exercise timing, duration or exercise FITT factors may be the result of comparing the effects of different combinations of exercise-related characteristics. For example, the exercise effect as a function of intervention duration may be influenced by the difference between supervised exercise interventions, which predominantly have an intervention duration of less than 12 weeks and unsupervised exercise interventions with a longer intervention duration. To further disentangle the effects of different intervention and exercise-related factors, it is necessary to conduct second-generation studies that directly compare different intervention and exercise-related characteristics, focusing on one aspect while keeping others similar. ${ }^{9} 49115118$

\section{Quality assessment}

Most studies showed high quality regarding random sequence generation and allocation concealment. A large number of studies had limited missing data or used an appropriate imputation technique. However, more than $40 \%$ of exercise arms were rated with high risk of adherence bias. Possibly, this bias could explain the small effect sizes found in the current meta-analysis. Adherence to unsupervised exercise is difficult to monitor, and small effects of unsupervised exercise could be a result of low adherence to the prescribed exercise programme. More than $75 \%$ of included exercise arms did not report any information on contamination, while high contamination could result in small pooled effect sizes. Overall, the quality of studies included in the current meta-analysis was higher than studies not included; this finding holds for all of the quality items assessed.

\section{Strengths and limitations}

Strengths of the current meta-analysis are the extensive search in multiple databases, the inclusion of RCTs and the large number of exercise arms, allowing subgroup analyses based on intervention and exercise-related characteristics. There are, however, several limitations. First, subgroups were based on exercise prescription that depended on whether the researchers have specifically appointed the intensity (ie, $\%$ maximum heart rate or maximum rate of oxygen consumption) and whether they have measured and reported the intensity correctly. In addition, a large number of studies did not report information on exercise adherence. Accordingly, subgroups could be categorised differently if they were based on the exercise actually performed by the patients. Second, in eight studies, two exercise arms were included, which we both compared with the same control group as if they were independent. This decision may have reduced the heterogeneity in effects and could result in a small bias in the pooled effect size. ${ }^{119}$

\section{Conclusion}

In conclusion, the results of our meta-analysis indicate that exercise interventions can improve self-reported QoL and PF compared with usual care. We found a statistically significant difference in effect between supervised exercise and unsupervised exercise. Supervised exercise interventions had statistically significant beneficial effects on QoL and PF, while unsupervised exercise interventions had no statistically significant effect on QoL and PF. For unsupervised exercise, weekly energy expenditure was a determinant of success.

Future studies should identify the most optimal combination of weekly exercise volume and intensity. Exercise intervention effects were comparable across subgroups based on timing and 
What is already known?

Previous randomised controlled trials (RCTs) and meta-analyses have demonstrated beneficial effects of exercise during and following cancer treatment on self-reported quality of life and self-reported physical function.

\section{What are the findings?}

- We found a significant between-group difference for exercise delivery mode, with significant beneficial effects for supervised exercise interventions on quality of life and physical function, but not for unsupervised interventions.

- No significant differences in intervention effects were found for variations in intervention timing and duration, or exercise frequency, intensity, type or time.

- Unsupervised exercise intervention effects on self-reported physical function were larger when prescribed at a higher weekly energy expenditure.

duration of intervention delivery and exercise FITT factors. Nevertheless, only adequately powered, high-quality RCTs can determine the causal effects of manipulating each exercise factor on outcomes in patients with cancer.

\section{Author affiliations}

'Department of Epidemiology and Biostatistics, Amsterdam Public Health Institute, VU University Medical Center, Amsterdam, The Netherlands

${ }^{2}$ Cancer Center Amsterdam, VU University Medical Center, Amsterdam, The Netherlands

${ }^{3}$ Department of Public and Occupational Health, Amsterdam Public Health Institute, VU University Medical Center, Amsterdam, The Netherlands

${ }^{4}$ Department of Otolaryngology-Head and Neck Surgery, VU University Medical

Center, Amsterdam, The Netherlands

${ }^{5}$ Department of Clinical Psychology, Vrije Universiteit, Amsterdam, The Netherlands

${ }^{6}$ Faculty of Physical Education and Recreation, University of Alberta, Edmonton,

Alberta, Canada

${ }^{7}$ Exercise Medicine Research Institute, Edith Cowan University, Joondalup, Western Australia, Australia

${ }^{8}$ Division of Psychosocial Research and Epidemiology, Netherlands Cancer Institute, Amsterdam, The Netherlands

${ }^{9}$ Division of Population Science, Moffitt Cancer Center and Research Institute,

Amsterdam, The Netherlands

${ }^{10}$ Amsterdam School of Communication Research (ASCOR), University of Amsterdam, Amsterdam, The Netherlands

${ }^{11}$ Department of Medical Oncology, VU University Medical Center, Amsterdam, The Netherlands

Correction notice This article has been corrected since it was published Online First. Figure 2B has been corrected.

Contributors MGS, TMA, MJC, LMB and JB contributed to the concept and design of the study. MGS, TMA, LMB and JK gathered and analysed the data. This study was performed alongside the POLARIS study. LMB, JB and IMVdL are members of the steering committee of POLARIS. KSC, RUN, PBJ and NKA are members of the international advisory board of POLARIS. All authors have revised the manuscript and approved the final version.

Funding Via 'Bas Mulder Award' granted to LMB by the Alpe d'HuZes Foundation/ Dutch Cancer Society (VU 2011-5045).

Competing interests None declared.

Ethics approval Ethics committee from local institutes where randomised controlled trials were conducted, which are included in this review/meta-analysis.

Provenance and peer review Not commissioned; externally peer reviewed.

(c) Article author(s) (or their employer(s) unless otherwise stated in the text of the article) 2018. All rights reserved. No commercial use is permitted unless otherwise expressly granted.

\section{REFERENCES}

1 Duijts SF, Faber MM, Oldenburg HS, et al. Effectiveness of behavioral techniques and physical exercise on psychosocial functioning and health-related quality of life in breast cancer patients and survivors-a meta-analysis. Psychooncology 2011;20:115-26.

2 Speck RM, Courneya KS, Mâsse LC, et al. An update of controlled physical activity trials in cancer survivors: a systematic review and meta-analysis. J Cancer Surviv 2010:4:87-100

3 Courneya KS, Mackey JR, Bell GJ, et al. Randomized controlled trial of exercise training in postmenopausal breast cancer survivors: cardiopulmonary and quality of life outcomes. J Clin Oncol 2003;21:1660-8.

4 Kampshoff CS, Chinapaw MJ, Brug J, et al. Randomized controlled trial of the effects of high intensity and low-to-moderate intensity exercise on physical fitness and fatigue in cancer survivors: results of the Resistance and Endurance exercise After ChemoTherapy (REACT) study. BMC Med 2015;13:275.

5 Knobf MT, Musanti R, Dorward J. Exercise and quality of life outcomes in patients with cancer. Semin Oncol Nurs 2007;23:285-96.

6 Billinger SA, Boyne P, Coughenour E, et al. Does aerobic exercise and the FITT principle fit into stroke recovery? Curr Neurol Neurosci Rep 2015;15:519.

7 Mishra SI, Scherer RW, Geigle PM, et al. Exercise interventions on healthrelated quality of life for cancer survivors. Cochrane Database Syst Rev 2012:8:CD007566

8 Mishra SI, Scherer RW, Snyder C, et al. Exercise interventions on health-related quality of life for people with cancer during active treatment. Cochrane Database Syst Rev 2012;8:CD008465.

9 Courneya KS, McKenzie DC, Mackey JR, et al. Effects of exercise dose and type during breast cancer chemotherapy: multicenter randomized trial. J Natl Cancer Inst 2013;105:1821-32.

10 Segal RJ, Reid RD, Courneya KS, et al. Randomized controlled trial of resistance or aerobic exercise in men receiving radiation therapy for prostate cancer. J Clin Oncol 2009:27:344-51.

11 Buffart LM, Kalter J, Chinapaw MJ, et al. Predicting OptimaL cAncer Rehabllitation and Supportive care (POLARIS): rationale and design for meta-analyses of individual patient data of randomized controlled trials that evaluate the effect of physical activity and psychosocial interventions on health-related quality of life in cancer survivors. Syst Rev 2013;2:75

12 Courneya KS, Segal RJ, Mackey JR, et al. Effects of aerobic and resistance exercise in breast cancer patients receiving adjuvant chemotherapy: a multicenter randomized controlled trial. J Clin Oncol 2007:25:4396-404.

13 Ferrer RA, Huedo-Medina TB, Johnson BT, et al. Exercise interventions for cancer survivors: a meta-analysis of quality of life outcomes. Ann Behav Med 2011:41:32-47.

14 Buffart LM, Kalter J, Sweegers MG, et al. Effects and moderators of exercise on quality of life and physical function in patients with cancer: An individual patient data meta-analysis of 34 RCTs. Cancer Treat Rev 2017;52:91-104.

15 Higgins JP, Altman DG, Gøtzsche PC, et al. The Cochrane Collaboration's tool for assessing risk of bias in randomised trials. BMJ 2011;343:d5928.

16 Brazier JE, Harper R, Jones NM, et al. Validating the SF-36 health survey questionnaire: new outcome measure for primary care. BMJ 1992;305:160-4.

17 Padilla GV, Presant C, Grant MM, et al. Quality of life index for patients with cancer. Res Nurs Health 1983;6:117-26.

18 Locke DE, Decker PA, Sloan JA, et al. Validation of single-item linear analog scale assessment of quality of life in neuro-oncology patients. J Pain Symptom Manage 2007:34:628-38

19 Aaronson NK, Ahmedzai S, Bergman B, et al. The European Organization for Research and Treatment of Cancer QLQ-C30: a quality-of-life instrument for use in international clinical trials in oncology. J Natl Cancer Inst 1993;85:365-76.

20 Schag CA, Ganz PA, Heinrich RL. CAncer Rehabilitation Evaluation System-short form (CARES-SF). A cancer specific rehabilitation and quality of life instrument. Cancer 1991;68:1406-13.

21 Overcash J, Extermann M, Parr J, et al. Validity and reliability of the FACT-G scale for use in the older person with cancer. Am J Clin Oncol 2001;24:591-6

22 Cuijpers P. Meta-analyses in mental health research. A practical guide. Amsterdam: VU University Amsterdam, 2016

23 Borenstein M. Effect sizes for continuous data. In: Cooper H, Hedges LV, Valentine JC, eds. The handbook of research synthesis and meta-analysis. 2nd edition. New York: Russell Sage Foundation, 2009:221-54.

24 Cohen J. Statistical power analysis for the behavioral sciences. Orlando: Academic Press, 1977

25 Durlak JA. How to select, calculate, and interpret effect sizes. J Pediatr Psychol 2009:34:917-28.

26 Higgins JP, Thompson SG, Deeks JJ, et al. Measuring inconsistency in meta-analyses. BMJ 2003:327:557-60.

27 Courneya KS, Friedenreich CM. Physical activity and cancer control. Semin Oncol Nurs 2007;23:242-52.

28 American College of Sports Medicine. ACSM's guidelines for exercise testing and prescription. 9th edition: Wolters Kluwer, Lippincott Williams \& Wilkins, 2014. 
29 Haskell WL, Lee IM, Pate RR, et al. Physical activity and public health: updated recommendation for adults from the American College of Sports Medicine and the American Heart Association. Med Sci Sports Exerc 2007;39:1423-34.

30 Cuijpers P, Smit F, Bohlmeijer E, et al. Efficacy of cognitive-behavioural therapy and other psychological treatments for adult depression: meta-analytic study of publication bias. Br J Psychiatry 2010;196:173-8.

31 Ergun M, Eyigor S, Karaca B, et al. Effects of exercise on angiogenesis and apoptosisrelated molecules, quality of life, fatigue and depression in breast cancer patients. Eur J Cancer Care 2013;22:626-37.

32 Hayes SC, Rye S, Disipio T, et al. Exercise for health: a randomized, controlled trial evaluating the impact of a pragmatic, translational exercise intervention on the quality of life, function and treatment-related side effects following breast cancer. Breast Cancer Res Treat 2013;137:175-86.

33 Kampshoff CS, Buffart LM, Schep G, et al. Design of the Resistance and Endurance exercise After ChemoTherapy (REACT) study: a randomized controlled trial to evaluate the effectiveness and cost-effectiveness of exercise interventions after chemotherapy on physical fitness and fatigue. BMC Cancer 2010;10:658.

34 Segal R, Evans W, Johnson D, et al. Structured exercise improves physical functioning in women with stages I and II breast cancer: results of a randomized controlled trial. J Clin Oncol 2001;19:657-65.

35 van Waart H, Stuiver MM, van Harten WH, et al. Effect of Low-Intensity Physical Activity and Moderate- to High-Intensity Physical Exercise During Adjuvant Chemotherapy on Physical Fitness, Fatigue, and Chemotherapy Completion Rates: Results of the PACES Randomized Clinical Trial. J Clin Oncol 2015;33:1918-27.

36 Short CE, James EL, Girgis A, et al. Main outcomes of the Move More for Life Trial: a randomised controlled trial examining the effects of tailored-print and targetedprint materials for promoting physical activity among post-treatment breast cancer survivors. Psychooncology 2015;24.

37 Schmidt T, Weisser B, Dürkop J, et al. Comparing Endurance and Resistance Training with Standard Care during Chemotherapy for Patients with Primary Breast Cancer. Anticancer Res 2015;35:5623-9.

38 Alibhai SM, O'Neill S, Fisher-Schlombs K, et al. A pilot phase II RCT of a home-based exercise intervention for survivors of AML. Support Care Cancer 2014;22:881-9.

39 Goedendorp MM, Peters ME, Gielissen MF, et al. Is increasing physical activity necessary to diminish fatigue during cancer treatment? Comparing cognitive behavior therapy and a brief nursing intervention with usual care in a multicenter randomized controlled trial. Oncologist 2010;15:1122-32.

40 Griffith K, Wenzel J, Shang J, et al. Impact of a walking intervention on cardiorespiratory fitness, self-reported physical function, and pain in patients undergoing treatment for solid tumors. Cancer 2009;115:4874-84.

41 Mehnert A, Veers S, Howaldt D, et al. Effects of a physical exercise rehabilitation group program on anxiety, depression, body image, and health-related quality of life among breast cancer patients. Onkologie 2011;34:248-53.

42 Thorsen L, Skovlund E, Strømme SB, et al. Effectiveness of physical activity on cardiorespiratory fitness and health-related quality of life in young and middle-aged cancer patients shortly after chemotherapy. J Clin Oncol 2005;23:2378-88.

43 Winters-Stone KM, Dobek J, Nail LM, et al. Impact + resistance training improves bone health and body composition in prematurely menopausal breast cancer survivors: a randomized controlled trial. Osteoporos Int 2013;24:1637-46.

44 Alibhai SM, Durbano S, Breunis H, et al. A phase II exercise randomized controlled trial for patients with acute myeloid leukemia undergoing induction chemotherapy. Leuk Res 2015:1178-86.

45 Porserud A, Sherif A, Tollbäck A. The effects of a physical exercise programme after radical cystectomy for urinary bladder cancer. A pilot randomized controlled trial. Clin Rehabil 2014;28:451-9.

46 Speck RM, Gross CR, Hormes JM, et al. Changes in the Body Image and Relationship Scale following a one-year strength training trial for breast cancer survivors with or at risk for lymphedema. Breast Cancer Res Treat 2010;121:421-30.

47 Arbane G, Tropman D, Jackson D, et al. Evaluation of an early exercise intervention after thoracotomy for non-small cell lung cancer (NSCLC), effects on quality of life, muscle strength and exercise tolerance: randomised controlled trial. Lung Cancer 2011;71:229-34

48 Cornette T, Vincent F, Mandigout S, et al. Effects of home-based exercise training on VO2 in breast cancer patients under adjuvant or neoadjuvant chemotherapy (SAPA) a randomized controlled trial. Eur J Phys Rehabil Med 2016;52:223-32.

49 Courneya KS, Sellar CM, Stevinson C, et al. Randomized controlled trial of the effects of aerobic exercise on physical functioning and quality of life in lymphoma patients. $J$ Clin Oncol 2009;27:4605-12.

50 Campbell A, Mutrie N, White F, et al. A pilot study of a supervised group exercise programme as a rehabilitation treatment for women with breast cancer receiving adjuvant treatment. Eur J Oncol Nurs 2005;9:56-63.

51 Cheville AL, Girardi J, Clark MM, et al. Therapeutic exercise during outpatient radiation therapy for advanced cancer: Feasibility and impact on physical well-being. Am J Phys Med Rehabil 2010;89:611-9.

52 Cheville AL, Kollasch J, Vandenberg J, et al. A home-based exercise program to improve function, fatigue, and sleep quality in patients with Stage IV lung and colorectal cancer: a randomized controlled trial. J Pain Symptom Manage 2013;45:811-21.
53 Herrero F, San Juan AF, Fleck SJ, et al. Combined aerobic and resistance training in breast cancer survivors: A randomized, controlled pilot trial. Int J Sports Med 2006;27:573-80.

54 Jacobsen PB, Phillips KM, Jim HS, et al. Effects of self-directed stress management training and home-based exercise on quality of life in cancer patients receiving chemotherapy: a randomized controlled trial. Psychooncology 2013;22:1229-35.

55 Jones LW, Douglas PS, Khouri MG, et al. Safety and efficacy of aerobic training in patients with cancer who have heart failure: an analysis of the HF-ACTION randomized trial. J Clin Oncol 2014;32:2496-502.

56 Ligibel JA, Meyerhardt J, Pierce JP, et al. Impact of a telephone-based physical activity intervention upon exercise behaviors and fitness in cancer survivors enrolled in a cooperative group setting. Breast Cancer Res Treat 2012;132:205-13.

57 McKenzie DC, Kalda AL. Effect of upper extremity exercise on secondary lymphedema in breast cancer patients: a pilot study. J Clin Oncol 2003;21:463-6.

58 Mock V, Frangakis C, Davidson NE, et al. Exercise manages fatigue during breast cancer treatment: a randomized controlled trial. Psychooncology 2005;14:464-77.

59 Mock V, Pickett M, Ropka ME, et al. Fatigue and quality of life outcomes of exercise during cancer treatment. Cancer Pract 2001;9:119-27.

60 Saarto T, Penttinen HM, Sievänen $\mathrm{H}$, et al. Effectiveness of a 12-month exercise program on physical performance and quality of life of breast cancer survivors. Anticancer Res 2012:32:3875-84.

61 Samuel SR, Maiya GA, Babu AS, et al. Effect of exercise training on functional capacity \& quality of life in head \& neck cancer patients receiving chemoradiotherapy. Indian J Med Res 2013;137:515-20.

62 Stigt JA, Uil SM, van Riesen SJ, et al. A randomized controlled trial of postthoracotomy pulmonary rehabilitation in patients with resectable lung cancer. J Thorac Oncol 2013;8:214-21.

63 Streckmann F, Kneis S, Leifert JA, et al. Exercise program improves therapy-related side-effects and quality of life in lymphoma patients undergoing therapy. Ann Oncol 2014;25:493-9

64 Yeo TP, Burrell SA, Sauter PK, et al. A progressive postresection walking program significantly improves fatigue and health-related quality of life in pancreas and periampullary cancer patients. J Am Coll Surg 2012;214:463-75.

65 Zhao SG, Alexander NB, Djuric Z, et al. Maintaining physical activity during head and neck cancer treatment: Results of a pilot controlled trial. Head Neck 2016;38(Suppl 1):E1086-96.

66 Ligibel JA, Giobbie-Hurder A, Shockro L, et al. Randomized trial of a physical activity intervention in women with metastatic breast cancer. Cancer 2016;122:1169-77.

67 Cadmus LA, Salovey P, Yu H, et al. Exercise and quality of life during and after treatment for breast cancer: results of two randomized controlled trials. Psychooncology 2009;18:343-52.

68 Daley AJ, Crank H, Saxton JM, et al. Randomized trial of exercise therapy in women treated for breast cancer. J Clin Oncol 2007:25:1713-21.

69 Duijts SF, van Beurden M, Oldenburg HS, et al. Efficacy of cognitive behavioral therapy and physical exercise in alleviating treatment-induced menopausal symptoms in patients with breast cancer: results of a randomized, controlled, multicenter trial. J Clin Oncol 2012;30:4124-33.

70 Irwin ML, Varma K, Alvarez-Reeves M, et al. Randomized controlled trial of aerobic exercise on insulin and insulin-like growth factors in breast cancer survivors: the Yale Exercise and Survivorship study. Cancer Epidemiol Biomarkers Prev 2009;18:306-13.

71 Milne HM, Wallman KE, Gordon S, et al. Effects of a combined aerobic and resistance exercise program in breast cancer survivors: a randomized controlled trial. Breast Cancer Res Treat 2008;108:279-88.

72 Mutrie N, Campbell AM, Whyte F, et al. Benefits of supervised group exercise programme for women being treated for early stage breast cancer: pragmatic randomised controlled trial. BMJ 2007:334:517.

73 Ohira T, Schmitz KH, Ahmed RL, et al. Effects of weight training on quality of life in recent breast cancer survivors: the Weight Training for Breast Cancer Survivors (WTBS) study. Cancer 2006;106:2076-83.

74 Steindorf K, Schmidt ME, Klassen 0, et al. Randomized, controlled trial of resistance training in breast cancer patients receiving adjuvant radiotherapy: results on cancerrelated fatigue and quality of life. Ann Oncol 2014;25:2237-43.

75 Travier N, Velthuis MJ, Steins Bisschop CN, et al. Effects of an 18-week exercise programme started early during breast cancer treatment: a randomised controlled trial. BMC Med 2015;13:121.

76 Winters-Stone KM, Dobek J, Bennett JA, et al. The effect of resistance training on muscle strength and physical function in older, postmenopausal breast cancer survivors: a randomized controlled trial. J Cancer Surviv 2012;6:189-99.

77 Murtezani A, Ibraimi Z, Bakalli A, et al. No. 2 The effect of aerobic exercise on quality of life among breast cancer survivors: a randomized controlled trial. $P m R$ 2014;6:S83-64.

78 Al-Majid S, Wilson LD, Rakovski C, et al. Effects of exercise on biobehavioral outcomes of fatigue during cancer treatment: results of a feasibility study. Biol Res Nurs 2015:17:40-8.

79 Hornsby WE, Douglas PS, West MJ, et al. Safety and efficacy of aerobic training in operable breast cancer patients receiving neoadjuvant chemotherapy: a phase II randomized trial. Acta Oncol 2014;53:65-74. 
80 Schmidt ME, Wiskemann J, Armbrust P, et al. Effects of resistance exercise on fatigue and quality of life in breast cancer patients undergoing adjuvant chemotherapy: A randomized controlled trial. Int J Cancer 2015;137:471-80.

81 Cormie P, Galvão DA, Spry N, et al. Can supervised exercise prevent treatment toxicity in patients with prostate cancer initiating androgen-deprivation therapy: a randomised controlled trial. BJU Int 2015;115:256-66.

82 Culos-Reed SN, Robinson JW, Lau H, et al. Physical activity for men receiving androgen deprivation therapy for prostate cancer: benefits from a 16-week intervention. Support Care Cancer 2010;18:591-9.

83 Galvão DA, Taaffe DR, Spry N, et al. Combined resistance and aerobic exercise program reverses muscle loss in men undergoing androgen suppression therapy for prostate cancer without bone metastases: a randomized controlled trial. J Clin Oncol 2010;28:340-7.

84 Galvão DA, Spry N, Denham J, et al. A multicentre year-long randomised controlled trial of exercise training targeting physical functioning in men with prostate cancer previously treated with androgen suppression and radiation from TROG 03.04 RADAR. Eur Urol 2014:65:856-64.

85 Monga U, Garber SL, Thornby J, et al. Exercise prevents fatigue and improves quality of life in prostate cancer patients undergoing radiotherapy. Arch Phys Med Rehabil 2007;88:1416-22.

86 Segal RJ, Reid RD, Courneya KS, et al. Resistance exercise in men receiving androgen deprivation therapy for prostate cancer. J Clin Oncol 2003;21:1653-9.

87 Winters-Stone KM, Dobek JC, Bennett JA, et al. Resistance training reduces disability in prostate cancer survivors on androgen deprivation therapy: evidence from a randomized controlled trial. Arch Phys Med Rehabil 2015;96:7-14.

88 Nilsen TS, Raastad T, Skovlund E, et al. Effects of strength training on body composition, physical functioning, and quality of life in prostate cancer patients during androgen deprivation therapy. Acta Oncol 2015;54:1805-13.

89 Arbane G, Douiri A, Hart N, et al. Effect of postoperative physical training on activity after curative surgery for non-small cell lung cancer: a multicentre randomised controlled trial. Physiotherapy 2014;100:100-7.

90 Edvardsen $\mathrm{E}$, Skjønsberg $\mathrm{OH}$, Holme I, et al. High-intensity training following lung cancer surgery: a randomised controlled trial. Thorax 2015;70:244-50.

91 Henke CC, Cabri J, Fricke L, et al. Strength and endurance training in the treatment of lung cancer patients in stages IIIA/IIIB/IV. Support Care Cancer 2014;22:95-101.

92 Salhi B, Haenebalcke C, Perez-Bogerd S, et al. Rehabilitation in patients with radically treated respiratory cancer: A randomised controlled trial comparing two training modalities. Lung Cancer 2015;89:167-74.

93 Courneya KS, Friedenreich CM, Quinney HA, et al. A randomized trial of exercise and quality of life in colorectal cancer survivors. Eur J Cancer Care 2003;12:347-57.

94 Pinto BM, Papandonatos GD, Goldstein MG, et al. Home-based physical activity intervention for colorectal cancer survivors. Psychooncology 2013;22:54-64.

95 van Vulpen JK, Peeters PH, Velthuis MJ, et al. Effects of physical exercise during adjuvant breast cancer treatment on physical and psychosocial dimensions of cancer-related fatigue: A meta-analysis. Maturitas 2016;85:104-11.

96 Oechsle K, Aslan Z, Suesse Y, et al. Multimodal exercise training during myeloablative chemotherapy: a prospective randomized pilot trial. Support Care Cancer 2014:22:63-9.

97 Wiskemann J, Dreger P, Schwerdtfeger R, et al. Effects of a partly self-administered exercise program before, during, and after allogeneic stem cell transplantation. Blood 2011;117:2604-13

98 Donnelly CM, Blaney JM, Lowe-Strong A, et al. A randomised controlled trial testing the feasibility and efficacy of a physical activity behavioural change intervention in managing fatigue with gynaecological cancer survivors. Gynecol Oncol 2011:122:618-24

99 McNeely ML, Parliament M, Courneya KS, et al. A pilot study of a randomized controlled trial to evaluate the effects of progressive resistance exercise training on shoulder dysfunction caused by spinal accessory neurapraxia/neurectomy in head and neck cancer survivors. Head Neck 2004:26:518-30.
100 McNeely ML, Parliament MB, Seikaly H, et al. Effect of exercise on upper extremity pain and dysfunction in head and neck cancer survivors: a randomized controlled trial. Cancer 2008;113:214-22.

101 Adamsen L, Quist M, Andersen C, et al. Effect of a multimodal high intensity exercise intervention in cancer patients undergoing chemotherapy: randomised controlled trial. BMJ 2009;339:b3410.

102 Backman M, Wengström Y, Johansson B, et al. A randomized pilot study with daily walking during adjuvant chemotherapy for patients with breast and colorectal cancer. Acta Oncol 2014;53:510-20.

103 Bennett JA, Lyons KS, Winters-Stone K, et al. Motivational interviewing to increase physical activity in long-term cancer survivors: a randomized controlled trial. Nurs Res 2007;56:18-27.

104 Broderick JM, Guinan E, Kennedy MJ, et al. Feasibility and efficacy of a supervised exercise intervention in de-conditioned cancer survivors during the early survivorship phase: the PEACH trial. J Cancer Surviv 2013;7:551-62.

105 Burnham TR, Wilcox A. Effects of exercise on physiological and psychological variables in cancer survivors. Med Sci Sports Exerc 2002;34:1863-7.

106 Korstjens I, May AM, van Weert E, et al. Quality of life after self-management cancer rehabilitation: a randomized controlled trial comparing physical and cognitive-behavioral training versus physical training. Psychosom Med 2008;70:422-9.

107 Mustian KM, Peppone L, Darling TV, et al. A 4-week home-based aerobic and resistance exercise program during radiation therapy: a pilot randomized clinical trial. J Support Oncol 2009:7:158-67.

108 Tang MF, Liou TH, Lin CC. Improving sleep quality for cancer patients: benefits of a home-based exercise intervention. Support Care Cancer 2010;18:1329-39.

109 Capozzi LC, McNeely ML, Lau HY, et al. Patient-reported outcomes, body composition, and nutrition status in patients with head and neck cancer: Results from an exploratory randomized controlled exercise trial. Cancer 2016;122:1185-200.

110 Knols RH, de Bruin ED, Uebelhart D, et al. Effects of an outpatient physical exercise program on hematopoietic stem-cell transplantation recipients: a randomized clinical trial. Bone Marrow Transplant 2011:46:1245-55.

111 Furzer BJ, Ackland TR, Wallman KE, et al. A randomised controlled trial comparing the effects of a 12-week supervised exercise versus usual care on outcomes in haematological cancer patients. Support Care Cancer 2016;24:1697-707.

112 Schwartz CE, Andresen EM, Nosek MA, et al. Response shift theory: important implications for measuring quality of life in people with disability. Arch Phys Med Rehabil 2007;88:529-36.

113 Courneya KS, Friedenreich CM. Framework PEACE: an organizational model for examining physical exercise across the cancer experience. Ann Behav Med 2001;23:263-72

114 Knols R, Aaronson NK, Uebelhart D, et al. Physical exercise in cancer patients during and after medical treatment: a systematic review of randomized and controlled clinical trials. J Clin Oncol 2005;23:3830-42.

115 Norris MK, Bell GJ, North S, et al. Effects of resistance training frequency on physica functioning and quality of life in prostate cancer survivors: a pilot randomized controlled trial. Prostate Cancer Prostatic Dis 2015:18:281-7.

116 Gollhofer SM, Wiskemann J, Schmidt ME, et al. Factors influencing participation in a randomized controlled resistance exercise intervention study in breast cancer patients during radiotherapy. BMC Cancer 2015;15:186.

117 Kampshoff CS, Jansen F, van Mechelen W, et al. Determinants of exercise adherence and maintenance among cancer survivors: a systematic review. Int J Behav Nutr Phys Act 2014;11:80

118 Buffart LM, Galvão DA, Brug J, et al. Evidence-based physical activity guidelines for cancer survivors: current guidelines, knowledge gaps and future research directions. Cancer Treat Rev 2014;40:327-40.

119 Cuijpers P, van Straten A, van Schaik A, et al. Psychological treatment of depression in primary care: a meta-analysis. Br J Gen Pract 2009:59:51-60. 